\title{
JeddahDashboard (JDB): Visualization of Open Government Data in Kingdom of Saudi Arabia
}

\author{
Mashael Khayyat ${ }^{1}$ \\ University of Jeddah, College of Computer science and Engineering \\ Department of Information Systems and Technology \\ Jeddah, Saudi Arabia
}

\begin{abstract}
Open data is data that anyone can freely use, access and redistribute without financial, legal or even technical restrictions. Accordingly, all governmental and non-governmental organizations may publish data that they own open for various purposes on the Internet without any restrictions such as (climate statistics, education statistics, transportation, industry, water abstraction, etc.). Further, Open Government Data (OGD) initiatives are proliferated in every country including Kingdom of Saudi Arabia (KSA). OGD should supposedly escalate the transparency, collaboration, and participation of citizens towards using OGD. However, the presentation of OGD format may not be attractive enough to users and vice-versa the data may not be easy for them to understand and interpret. These stumbling blocks may dampen the use of OGD among citizens. The problems can be resolved through visualization of the available data sets and to represent these data in accordance to user preference. This research emphasizes on visualization efforts of OGD in KSA named JeddahDashboard (JDB) website. The aim of creating JeddahDashBoard is to visualize the published government data in KSA. The idea was inspired by the DublinDashBoard in Ireland where data and real-time information, time series index data, and interactive maps on vast aspects of the city are provided mostly in an interactive ways and attractive charts that are easy to understand. In order to create JeddahDashBoard, two tools were used "the tableau" and then "chart.js" because the later was simple and flexible. Finally, this paper shares researchers experience and challenges in establishing JDB.
\end{abstract}

Keywords - Open Data; Open Government Data; visualization; Dashboard; Saudi Arabia; KSA

\section{INTRODUCTION}

In the nutshells, Open Data can be defined as "an approach to managing data so that it enables the structured free flow of non-sensitive information to those who have the need or interest in using this information. It allows different types of users to access, organize and use data in ways that make sense to them" [1], [2]. Or simply can mean the kind of data which is open for anyone to access, modify, reuse, and share. Open Data derives its label from various open-source, open government, open science, etc. [3]. Governments, independent organizations, and agencies have come forward to create more open data for free and easy access [4].

Open data is important because the world has increasingly adapted data-driven [5], [6]. But if there are restrictions on the access and the format of how those Open Data are presented, the idea of data-driven business and governance will be difficult to be realized. Therefore, the quality of open data must be good which will enhance fuller understanding among citizens and can strengthen democracy. The understanding of Open Data is normally associated with the most impactful way the Open Data are presented, bearing in mind the purpose of sharing them with the targeted end-users. This directly demands data visualization perspectives. However, trying to decide which visualization type works for the specific Open Data, can be tough [7]. Users see various types of data visualizations each day. Some are beautiful but provide little insight. Some are functional, allowing the viewers to draw conclusions at a glance, but not aesthetic. Above all, the provider's goal, the structure, and size of the underlying Open Data will normally determine when to use one type of visualization over another.

Open data is not very new idea in the Kingdom of Saudi Arabia [8],[9],[10], there is already a website called www.data.gov.sa, which provides Open Government Data (OGD) to serve citizens, but the method of providing data could be not attractive to the users and the data can be difficult to be understood. Thus, to solve these problems we come up with the idea of visualizing the available data and the concept of our project is to represent this data in an attractive way so that more users can be interested to deal with the OGD and make use of it.

The next section explains the research background and related work. Then, experiment and results followed by discussions. Finally, conclusions and future work are described.

\section{RESEARCH BACKGROUND AND RELATED WORK}

\section{A. OGD and Principles of OGD Initiatives}

Recently, government organizations and agencies have been adopting OGD initiatives globally to achieve many benefits such as institutional, social, cultural, economic and political benefits [11]. There are two major reasons for opening government data. Firstly, is the positive impact it will have on citizens which includes greater awareness of what the government does, cognizance of how their taxes are spent, and improved civic engagement. Next, the benefits that governments can realize such as increased civic trust in government, greater efficiency, and enhanced delivery of services or systems functions. 


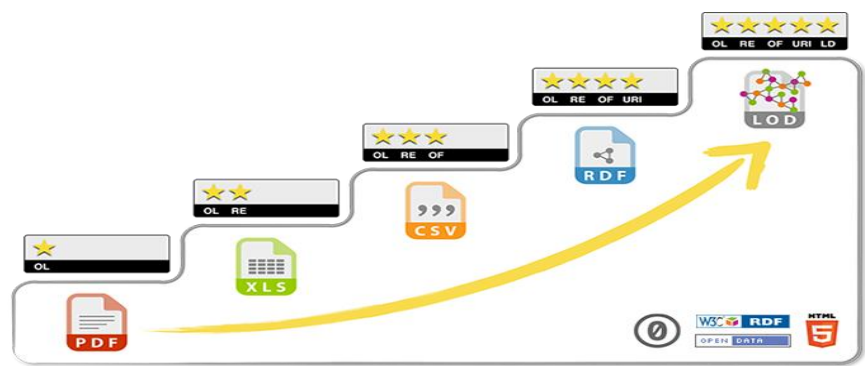

Fig 1. Classification of open data [17].

OGD has also been adopted among government institutions in KSA. As in [12], "The adoption of OGD was influenced by existing institutional arrangements and landscapes occurring in the country such as the Saudi Vision 2030, the approval of the Freedom of information Act 2016, and anti-corruption campaigns which have contributed positively to the transition from culture of secrecy to openness" [12]. In [12] further emphasized that the OGD initiative is influenced by both the internal and external institutional pressures. In [12] also confirmed that, the organizations involved in his study has obtained many benefits, which can be described as "rationalized myths" which he elaborate as "transparency and accountability, better access to government data, support for innovation, improved government services, operational benefits and encouragement of participation" [12].

The organization for Economic Co-operation and Development (OECD) [13] defines open government as the opening of government processes, proceedings, documents, and data for public scrutiny and involvement. Eight principles have been identified to guide open government initiatives. The principles [14], [15] include the following:

- All public data should be made available. "Public" data refers to information that isn't subject to valid privacy, security, or privilege limitations.

- Data is collected at its primary source, and it isn't modified or presented in aggregate.

- Data is made available in a timely fashion so that it's valuable and useful.

- Data is accessible to the widest number of users for the widest range of purposes.

- Data is structured so that it can be processed by a machine.

- Data is available to anyone, and no one needs to register to access it.

- Data is available in a non-proprietary format - no one has exclusive control over it.

- Data is license-free, and not subject to any copyright, patent, trademark, or trade secret regulations. However, reasonable privacy, security, and privilege restrictions are acceptable.

- Seven additional principles are added by the OpenGovData.org [16] to extend the OGD's principles. The extension of these principles is more to improve the quality, the safety of the retrieval, the authenticity, and the integrity of the information published on OGD as specified below:

- Data should be free, and it should be available online.

- Data should be made available at a stable internet location for an indefinite period, and it should remain in a stable data format for as long as possible.

- Data should be trustworthy. To that end, it should be digitally signed or include an attestation of the publication/creation date, its authenticity, and its integrity.

- There must be a presumption of openness. That is to say, the government must be proactive about making information public and available.

- The government must provide users with enough information for them to determine whether the information is accurate and current.

- Data must be safe to open, without executable content that can transmit worms, viruses, and malware.

- The government implements suggestions from the public about how to disseminate information.

Keeping in mind that open data can be available but with deferent level or classification as Tim Berners-Lee proposed. He proposed a five-step ranking system for data on the web as show the Fig. 1 [17].

In Fig. 1, one star means make your data available online in any format under an open license. Two starts data means they are structured such as in Excel file format. However, if the data in CSV instead of Excel (a non-proprietary open format) they will considered as three stars. Four stars data means that URIs have been used in order to enable people to point at datasets. Finally, five stars means the data are linked with other data to provide context.

\section{B. Open Data Visualization}

Citizens' interests, technical know-how and purpose for using OGD varies. Visualization is necessary to facilitate citizens who are less competence in technical know-how to use, understand and/or contribute to OGD initiatives. There are different types of visualizations of OGD which include table, graph, chart, and map. There exist many tools that can be used to create visualizations of OGD. Among them are given in Table I.

\section{OGD Problems and Proposed Solutions}

Government Data is open if and only if, it can be accessed and reused by any Internet users. However, there may be barriers to open data [18]. The barriers can be from the perspectives of either financial, legal and technical issues or the combination of them. For example, the barrier from the financial constraints is when data is not free; from the legal barriers is when legal permission to access data is imposed and from the technical barriers is when data is only confined to certain formats such as PDFs and Microsoft excel worksheet files. These formats can be complicated to understand and use 
without visualization. Thus, this research aims to offer visualization types according to users' preferences. This initiative is hopefully facilitating citizens to access and use OGD while inspiring some of them to publish data when they realize what they share is leveraged by others.

\section{Related OGD Initiatives Around the Globe}

For the purpose of lesson learnt, five related OGDs around the globe are selected randomly using convenience sampling and summarized in Table II. It briefly describes the initiatives in the perspectives of names, objectives and techniques used to develop them.

TABLE I. VISUALIZATION TOOLS

\begin{tabular}{|c|c|}
\hline Tool Name & Brief description Table Column Head \\
\hline Chart.js & $\begin{array}{l}\text { Chart.js is a community maintained open-source } \\
\text { library that helps you easily visualize data using } \\
\text { JavaScript. The library has two different versions. } \\
\text { The normal version, called Chart.js and } \\
\text { Chart.min.js, comes with the Chart.js library and a } \\
\text { color parser. The bundled version composed of } \\
\text { Chart.bundle.js or Chart.bundle.min.js. }\end{array}$ \\
\hline Tableau & $\begin{array}{l}\text { Tableau offers strong features for data discovery } \\
\text { and features such as data conversion, sorting and } \\
\text { filtering data. Tableau is a software suite that } \\
\text { enables users to create data visualization that may } \\
\text { be maps or graphs as it provides flexibility in } \\
\text { creating different types of graphs. The files are } \\
\text { CSV and databases rational and others. } \\
\text { Tableau is also a reporting tool for findings of } \\
\text { data analysis via a bar chart, pie chart and any } \\
\text { visualization technique. } \\
\text { Tableau has many extensions such as public } \\
\text { addition, personal addition and professional } \\
\text { addition. And the public addition connects many } \\
\text { data sources such as: Google sheets, Microsoft } \\
\text { excel 2007, Web data connectors and another data } \\
\text { source. }\end{array}$ \\
\hline Google Fusion Tables & $\begin{array}{l}\text { Google Fusion Table is a tool to visualize data on } \\
\text { the Excel file format as it allows users to create } \\
\text { their own spreadsheets by uploading CSV files } \\
\text { and allows charts from the spreadsheets that users } \\
\text { have. However, Fusion Tables, the API and } \\
\text { Embedded Fusion Tables visualizations (maps, } \\
\text { charts, tables and cards) have been discontinued } \\
\text { since August } 2019 \text { [19]. }\end{array}$ \\
\hline FusionCharts & $\begin{array}{l}\text { FusionCharts is a javaScript charts for web \& } \\
\text { mobile. It's the most comprehensive JavaScript } \\
\text { charting library, with over } 90+\text { charts and } 1000+ \\
\text { maps. From the basic charts (line, column, pie etc. } \\
\text { 2D \& 3D) to the most complex ones (waterfall, } \\
\text { gnat, candlestick, zoom line etc.). With } \\
\text { FusionCharts, it is easy to download/export all } \\
\text { your JavaScript charts to the format of your choice } \\
\text { - JPEG, PNG, PDF or SVG. All one need to do is } \\
\text { to include a single line of code. FusionCharts } \\
\text { Suite XT supports } 3 \text { modes of export namely, } \\
\text { Server-side export, Client-side export, and Auto } \\
\text { export (Default) (FusionCharts, 2018) [20]. }\end{array}$ \\
\hline
\end{tabular}

TABLE II. RELATED OGD INITIATIVES

\begin{tabular}{|c|c|c|}
\hline $\begin{array}{l}\text { OGD } \\
\text { Initiatives }\end{array}$ & Objective & Technique \\
\hline $\begin{array}{l}\text { OGD in } \\
\text { Brazil }\end{array}$ & $\begin{array}{l}\text { Brazil is one of the leading OGD } \\
\text { providers. The objectives of } \\
\text { Brazil OGD: } \\
\text { - To provide data without } \\
\text { financial costs. } \\
\text { To focus on data of } \\
\text { economy, trade, } \\
\text { environmental services, } \\
\text { population and others. } \\
\text { To encourage citizen } \\
\text { participation in the planning } \\
\text { and development of public } \\
\text { policies. }\end{array}$ & $\begin{array}{l}\text { Use many techniques } \\
\text { and programming } \\
\text { languages } \\
\text { to implement the } \\
\text { website which include: } \\
\text { Database. } \\
\text { - } \text { Web. } \\
\text { programing } \\
\text { - Power bi. }\end{array}$ \\
\hline $\begin{array}{l}\text { UK } \\
\text { Government } \\
\text { Data }\end{array}$ & $\begin{array}{l}\text { Government of the United } \\
\text { Kingdom has made data available } \\
\text { to the public free of charge via } \\
\text { the UK's open data website, } \\
\text { data.gov.uk. Through this } \\
\text { website, all governmental data } \\
\text { issued by ministries and official } \\
\text { institutions in UK. Open data are } \\
\text { presented in several format, } \\
\text { which include: PDF, JSON, } \\
\text { HTML\&RDF format. } \\
\text { - To provide data that meet } \\
\text { the needs of consumers of } \\
\text { such data. } \\
\text { To provide easy data } \\
\text { access. } \\
\text { To provide good } \\
\text { visualization varieties. }\end{array}$ & $\begin{array}{l}\text { Use many techniques } \\
\text { and programming } \\
\text { languages } \\
\text { to implement the } \\
\text { website as expected: } \\
-\quad \text { HTML. } \\
-\quad \text { JAVA } \\
\text { SCRIPIT. } \\
\text { - CSS. } \\
- \text { PHP. } \\
-\quad \text { XML. } \\
-\quad \text { Socrata } \\
\end{array}$ \\
\hline $\begin{array}{l}\text { The Dublin } \\
\text { Dashboard } \\
\text { (DDB) }\end{array}$ & $\begin{array}{l}\text { The DDB Initiative is web based } \\
\text { OGD system. DDB interacts with } \\
\text { user by collecting, analyzing data } \\
\text { from many sources about Dublin } \\
\text { in Ireland through interactive } \\
\text { maps, graphs and applications. } \\
\text { DDB objectives are: } \\
\text { - To provides data for free. } \\
\text { - To provides fast and easy } \\
\text { data retrieval to users, for } \\
\text { example checking their } \\
\text { traffic summons with } \\
\text { interactive maps. }\end{array}$ & $\begin{array}{l}\text { Use many techniques } \\
\text { and programming } \\
\text { languages } \\
\text { to implement the } \\
\text { website which include: } \\
\text { - HTML. } \\
\text { JAVA } \\
\text { SCRIPIT. } \\
\text { - CSS. } \\
\text { PHP. } \\
\text { XML } \\
\text { Web } \\
\text { programing. } \\
\text { Project } \\
\text { Open Data } \\
\text { Dashboard } \\
\text { tools. }\end{array}$ \\
\hline $\begin{array}{l}\text { Open Data } \\
\text { portal of } \\
\text { Saudi Arabia }\end{array}$ & $\begin{array}{l}\text { The main role of the portal is to } \\
\text { publish data sets for ministries } \\
\text { and government agencies in the } \\
\text { form of open data, and to make } \\
\text { this data available to all users. } \\
\text { - To enable users to access } \\
\text { and copy databases of } \\
\text { different ministries and } \\
\text { government agencies in } \\
\text { Saudi Arabia and copy } \\
\text { them and use them } \\
\text { according to certain rules. } \\
\text { To bridge the gap between } \\
\text { government agencies and } \\
\text { citizens, where citizens } \\
\text { benefit from data provided } \\
\text { in many ways. }\end{array}$ & $\begin{array}{l}\text { Use many techniques } \\
\text { and programming } \\
\text { languages } \\
\text { to implement the } \\
\text { website which include: } \\
\text { PHP. } \\
\text { - CSS. } \\
\text { - HTML. } \\
\text { Web } \\
\text { programing. }\end{array}$ \\
\hline
\end{tabular}




\begin{tabular}{|c|c|c|}
\hline \multirow{2}{*}{$\begin{array}{l}\text { OGD } \\
\text { Initiatives }\end{array}$} & Objective & \multirow[t]{2}{*}{ Technique } \\
\hline & $\begin{array}{l}\text { To expand e-government } \\
\text { services so that these efforts } \\
\text { reach individuals and } \\
\text { private sector organizations, } \\
\text { To improve transparency } \\
\text { and allow people to } \\
\text { showcase their creations. }\end{array}$ & \\
\hline $\begin{array}{l}\text { Open data } \\
\text { Princess } \\
\text { Nourah bint } \\
\text { Abdulrahman } \\
\text { University }\end{array}$ & $\begin{array}{l}\text { Princess Nourah bint } \\
\text { Abdulrahman University offers } \\
\text { an open data platform where all } \\
\text { students and beneficiaries can } \\
\text { benefit from the published data. } \\
\text { The library offers an open data } \\
\text { library on the University's } \\
\text { website, which contains } \\
\text { university files that include many } \\
\text { statistics. The initiative has many } \\
\text { objectives, including: } \\
\text { - To encourage electronic } \\
\text { participation of } \\
\text { governmental and non- } \\
\text { governmental entities. } \\
\text { - To enable users to access } \\
\text { data easily. } \\
\text { - To enhance transparency. } \\
\text { - To provides an open portal } \\
\text { containing files of different } \\
\text { data. }\end{array}$ & $\begin{array}{l}\text { Use many techniques } \\
\text { and programming } \\
\text { languages to } \\
\text { implement the website } \\
\text { which include: } \\
\text { - } \quad \text { HTML. } \\
\text { - JAVA } \\
\text { SCRIPIT. } \\
\text { Using } \\
\text { software of } \\
\text { Microsoft } \\
\text { office such } \\
\text { as Excel. } \\
\text { Can files be } \\
\text { viewed } \\
\text { directly } \\
\text { without the } \\
\text { need to use } \\
\text { specialized } \\
\text { software. }\end{array}$ \\
\hline
\end{tabular}

\section{EXPERIMENT AND RESULTS}

\section{A. Design, Development and Implementation of JDB}

In this research, the gateway for sharing and publishing KSA's OGD is created and named "JeddahDashBoard" (JDB). JDB is incorporating visualization preferences from the perspective of users or citizens. JDB is inspired by the "DublinDashBoard", in Ireland, where real-time information, time-series index data, and interactive maps on all aspects of the city information are provided. On the same note, JDB specifically enables citizens to obtain detailed, up-to-date information about Jeddah city that will help them make a dayto-day decision and promotes evidence-based analysis.

The design, development and implementation of JDB is following the standard procedures of system development life cycle. JDB users' requirements were conducted via online questionnaires towards 200 respondents. The researchers get $75 \%$ feedbacks ( 150 of respondents returned the feedbacks). In summary, the findings showed the highest percentage of respondent is those in the age range of 21-26 years. Most of them is interested in public services data. Their motivation to use and deal with open data is to learn new skills. Highest percentage of data format preferred by the respondents is in the PDF format. The functional requirements should include starting up the website, displaying the homepage, exhibiting: The Browse Categories, the Display Visualized Dataset and the Read About Website. The non-functional requirements of JDB include concern of user friendliness of its website, its security, accuracies, accessibilities and availabilities.
The software used during design and implementation as well as managing JDB varies. The Operating Systems used is Windows $(8 \& 10)$ while the software for managing the JDB Project is Microsoft Office Project 2013. The Microsoft Office Word (2013) was deployed for the documentation purposes. The Microsoft Office PowerPoint (2013) and Prezi was used for presentation, while Google Drive and Microsoft Excel Project (2010-2013) were utilized to prepare for online survey and statistics. Microsoft Visio (2013) was deployed for drawing diagrams and Low Fidelity Prototype by mock-ups and Microsoft access (2013-2010) were arranged to design the prototype of JDB. Finally, PHP, Cake PHP, MySQL, Notepad ++ , HTML, CSS, JavaScript, WAMP Server, Tableau, and Google Fusion were installed for JDB implementation.

There are nine database tables composed in JDB. The tables' names and their brief descriptions are listed in Table III.

100 participants were participated in the testing process. The breakdown of the participant is: 46 administrators (people in Municipality of Jeddah Governorate) to test and verify the administration functionalities of the JDB website and 54 users/citizens surround Jeddah (teachers and students of King of Abdul-Aziz University) to test the usability and reliability of the JDB website. The test was conducted from Sunday 25th March 2018 to Wednesday 28th March 2018.

\section{B. Difficulties of JDB Initiative}

As mentioned earlier, open data is not a very new idea in Saudi Arabia, and there is already a website called www.data.gov.sa, but the data are in spreadsheet format. JDB website offers visualizations to enable a user to view data according to the available charts she/he prefers which can facilitate his/her understanding of the data. For this study, researchers focus on open data from the education category first and make the data available only in three forms of chart namely: The Bar, the Pie and Line chart. Further, JDB is offering a useful function where a user can upload any excel file and convert the excel file to a chart of her/his preference (either a: bar, pie or line chart).

TABLE III. JDB DATABASE FILES COMPOSITION

\begin{tabular}{|l|l|}
\hline Table Name & Description \\
\hline About us page section & This table used to store page information \\
\hline Contact us massage & $\begin{array}{l}\text { This table contains messages from users who } \\
\text { want to communicate with us. }\end{array}$ \\
\hline News Letter & $\begin{array}{l}\text { This table contains the email of users who } \\
\text { subscribe to the latest site news. }\end{array}$ \\
\hline Site settings & $\begin{array}{l}\text { This table stores all figures and links of social } \\
\text { media. }\end{array}$ \\
\hline Admin & $\begin{array}{l}\text { This table contains the admin who controls the } \\
\text { website and updated. }\end{array}$ \\
\hline Chart type & $\begin{array}{l}\text { This table contains the chart types (Bar chart/Pie } \\
\text { chart/Line chart). }\end{array}$ \\
\hline File & $\begin{array}{l}\text { This table contains the files in the website in } \\
\text { each education data sets. }\end{array}$ \\
\hline File chart & This table contains the file with selecting chart. \\
\hline
\end{tabular}




\section{CONCLUSION AND FUTURE WORK}

The aim of this work was to utilize available OGD by visualizing the data. Furthermore, this work aimed at representing OGD in an attractive way so that more users can be interested to deal with the OGD and make use of it. However, as mentioned above, there were many difficulties faced to utilize the available open data. The main challenge was identifying the appropriate tool/ technique to visualizing the OGD. As mentioned above, "chart.js" tool was used for enabling the users to upload any excel file to visualize the data. Again, the implementation stage was quite challenging where the researchers have encountered problems in identifying the appropriate tools to visualize the spreadsheet files. The researchers have changed the tools of visualization twice. In the beginning, they learned "the tableau" tool and how to link it to JDB website. Then, many modifications have been requested from the academic staff that made them change the tool to a simple but flexible Java Script charting named "chart.js". The tool enables a user to upload any excel file to visualize the data.

Overall, there are many avenues to extend JDB initiative which can improve its quality and functionalities for the future research. The following include some interests:

- Extend the system to include all sectors (for example, Health, Taxation and Transportation) from the Saudi open data website (www.open.data.sa)

- Implement JBD system for mobile application

- Enable users to directly pull data from the "http://www.data.gov.sa/en" for live updated figures.

Further experimental studies are required for a detailed benchmark of this work with others. For example, JDB can be benchmarked with DublinDashBoard in Ireland where data and real-time information, time-series index data, and interactive maps on vast aspects of the city are provided mostly in interactive ways and attractive charts that are easy to understand.

\section{ACKNOWLEDGMENT}

I would like to thank prof. saadiah yahya for all her efforts and goodness, and my students malak al_nufaie, nourah al_subaie, salma al_muzaini, and shahad arbaein for all their contribution and efforts to achieve this work.

\section{REFERENCES}

[1] Cortada, J. W., Nix, V. A., \& Reyes, L. C. Opening up government: How to unleash the power of information for new economic growth. IBM Institute for Business Value. USA. 2011.

[2] ALGEMILI, Usamah A. Outstanding challenges in recent open government data initiatives. International Journal of e-Education, eBusiness, e-Management and e-Learning, 2016, 6.2: 91.

[3] Khayyat, Mashael Mahmoud. CO-CREATION WITH OPEN GOVERNMENT DATA. 2017.
[4] Khayyat, Mashael, and Frank Bannister. "Open data licensing: More than meets the eye." Information Polity 20.4 (2015): 231-252.

[5] MÜLLER, Dominic; REICHERT, Manfred; HERBST, Joachim. Flexibility of data-driven process structures. In: International Conference on Business Process Management. Springer, Berlin, Heidelberg, 2006. p. 181-192.

[6] KADLEC, Petr; GRBIĆ, Ratko; GABRYS, Bogdan. Review of adaptation mechanisms for data-driven soft sensors. Computers \& chemical engineering, 2011, 35.1: 1-24.

[7] WANG, Lidong; WANG, Guanghui; ALEXANDER, Cheryl Ann. Big data and visualization: methods, challenges and technology progress. Digital Technologies, 2015, 1.1: 33-38.

[8] SAXENA, Stuti. National open data frames across Japan, The Netherlands and Saudi Arabia: role of culture. foresight, 2018.

[9] ALRUSHAID, Marwah W.; SAUDAGAR, Abdul Khader Jilani. Measuring the data openness for the open data in Saudi Arabia eGovernment: A case study. International journal of advanced computer science and applications, 2016, 7.12: 113-122.

[10] ALANAZI, Jazem Mutared; CHATFIELD, Akemi. Sharing government-owned data with the public: a cross-country analysis of open data practice in the Middle East. 2012.

[11] WANG, Hui-Ju; LO, Jin. Adoption of open government data among government agencies. Government Information Quarterly, 2016, 33.1: 80-88.

[12] Altayar MS. Motivations for open data adoption: An institutional theory perspective. Government Information Quarterly. 2018 Oct 1;35(4):63343.

[13] OECD. 2018, [online] Available at: http://www.oecd.org/mena/governance/mena-oecd-opengovernment.htm [Accessed 2 Feb. 2020].

[14] Heusser, F. .Understanding Open Government Data and Addressing Its Impact: 2012.

[15] Sunlight Foundation. Ten Principles for Opening Up Government Information. [online] Available at: https://sunlightfoundation.com/policy/documents/ten-open-dataprinciples/, 2010.

[16] Opengovernmentdata.Org. Welcome to Open Government Data. [online] Available at: http://opengovernmentdata.org/,2016.

[17] 5stardata.info. 2017. 5-star Open Data. [online] Available at: http://5stardata.info/en/ [Accessed 2 Nov. 2017].

[18] Martin, S., Foulonneau, M., Turki, S., \& Ihadjadene, M. Risk Analysis to Overcome Barriers to Open Data. Electronic Journal of eGovernment, 11(1), 348-359. 2013.

[19] FAQ: Google Fusion Table [online] last update: 3 Dec 2019. Available at: https://support.google.com/fusiontables/answer [Accessed 17th Jan 2020] [

[20] Fusion Chart Development Centre [online] Available at: https://www.fusioncharts.com/dev/ [Accessed 17th Jan 2020].

\section{AUTHOR's PROFILE}

Mashael Khayyat is now the supervisor of the department of Computer and Network Engineering, and an assistance professor in the Department of Information Systems and Technology in the College of Computer Science and Engineering at the University of Jeddah. M. Khayyat has graduated with a Bachelor of Computer Science with an honor degree in 2004 from King AbdulAziz University. M. Khayyat earned a Master of Applied Information systems (AIS) from the Arab Academy for Science and Technology and Maritime Transport, Alexandria, Egypt. M. Khayyat received her second Master's degree in Technology Management (MTM) from the University of New South Wales (UNSW), Sydney, Australia. In 2017, M. Khayyat has granted a Ph.D. degree in Computer Science and statistics from Trinity College Dublin (TCD), Dublin, Ireland. 